\title{
The effect of nitrous oxide on the measurement of single-breath transfer factor
}

\author{
C.L. Phillips, R. Simmul, A.I. Smith, N. Berend
}

The effect of nitrous oxide on the measurement of single-breath transfer factor. C.L. Phillips, R. Simmul, A.I. Smith, N. Berend. CERS Journals Ltd 1997.

ABSTRACT: One hour after a bone marrow biopsy and inhalation of Entonox gas (50\% nitrous oxide $\left(\mathrm{N}_{2} \mathrm{O}\right)$ and $50 \%$ oxygen), a patient had a markedly reduced transfer factor of the lung for carbon monoxide $\left(T_{\mathrm{L}}, \mathrm{CO}\right)$. Three hours after Entonox, the patient had a normal $T_{\mathrm{L}}, \mathrm{CO}$. Since carbon monoxide (CO) and $\mathrm{N}_{2} \mathrm{O}$ have similar spectral wavelengths, it was proposed that residual $\mathrm{N}_{2} \mathrm{O}$ in the lungs was interfering with the infra-red analysers used to detect $\mathrm{CO}$ concentrations. Experiments were performed to verify the "interference" effect and its duration.

Five healthy volunteers performed serial triplicate $T \mathrm{~L}, \mathrm{CO}$ measurements over 3 $h$ on two randomized days (Control $v s \mathrm{~N}_{2} \mathrm{O}$ ). The first triplicate $T_{\mathrm{L}}$, CO on each day served as a baseline measurement. Following the baseline measurement on the $\mathrm{N}_{2} \mathrm{O}$ day, each subject inhaled Entonox for $\mathbf{1 0} \mathrm{min}$. To serve as a control for the infrared effect, the identical protocol was repeated using a gas chromatography method for $T \mathrm{~L}$, co determination.

The infra-red method showed a marked reduction (>50\%) in $T \mathrm{~L}, \mathrm{CO} 30 \mathrm{~min}$ after $\mathrm{N}_{2} \mathrm{O}$ inhalation. This reduction did not return to baseline levels for at least $2 \mathrm{~h}$. In comparison, the gas chromatography method showed no significant reduction in $T \mathrm{~L}, \mathrm{CO}$.

In a group of healthy nonsmoking subjects, $\mathrm{N}_{2} \mathrm{O}$ markedly affected the measurement of the transfer factor of the lungs for carbon monoxide using infra-red analysers. The time course over which the measurement was reduced was at least $\mathbf{2} \mathrm{h}$ for a $10 \mathrm{~min}$ inhalation period. The effect was entirely due to a measurement error associated with infra-red technology.

Eur Respir J., 1997; 10: 200-201.
Dept of Respiratory Medicine, Royal North Shore Hospital., St Leonards, NSW, Australia

Correspondence: C.L. Phillips

Respiratory Investigation Unit

Level 6, Main Block

Royal North Shore Hospital

St Leonards

NSW 2065

Australia

Keywords: Infra-red analysers nitrous oxide transfer factor of the lungs for carbon monoxide

Received: June 201996

Accepted after revision October 31996
Patients diagnosed with lymphoma and leukaemia routinely undergo pulmonary function tests, including single-breath transfer factor of the lungs for carbon monoxide $(T \mathrm{~L}, \mathrm{CO})$, before and in the months following bone marrow transplant. This group of patients receive a diverse regimen of therapy, including chemotherapy and total body irradiation, both of which have been shown to have adverse effects on the lungs. The serial lung function tests enable assessment of any adverse effects of therapy or detection of complications of transplantation. Staff in the pulmonary function laboratory may be unaware of procedures performed immediately prior to testing.

A chance observation in a patient with lymphoma revealed a markedly reduced $T \mathrm{~L}$, Co following a bone marrow biopsy $1 \mathrm{~h}$ previously. During this biopsy, Entonox gas (comprising $50 \%$ nitrous oxide $\left(\mathrm{N}_{2} \mathrm{O}\right)$ and $50 \%$ oxygen) was administered for analgesia for approximately 10 min. A normal TL,CO measurement was subsequently obtained $3 \mathrm{~h}$ after the Entonox inhalation. Since carbon monoxide $(\mathrm{CO})$ and $\mathrm{N}_{2} \mathrm{O}$ have similar spectral wavelengths [1], the hypothesis was proposed that residual $\mathrm{N}_{2} \mathrm{O}$ was still diffusing out of the blood and soft tissue and was subsequently interfering with the infra-red analysers used to detect $\mathrm{CO}$ concentrations during the $T_{\mathrm{L}}, \mathrm{CO}$ test. The false detection of $\mathrm{N}_{2} \mathrm{O}$ as $\mathrm{CO}$ would result in a markedly reduced $T \mathrm{~L}$,CO. Upon introducing Entonox directly into the gas sample tube for the infra-red analysers, the measured output for $\mathrm{CO}$ was substantially increased. A further series of experiments were carried out to verify the "gas interference" effect, and to document the time course over which this effect occurs following a $10 \mathrm{~min}$ inhalation of nitrous oxide.

\section{Materials and methods}

\section{Subjects}

Five healthy (nonsmoking) volunteers (4 males and 1 female) with a mean age of 41 yrs (range 34-48 yrs) were recruited for this study.

\section{Experimental protocols}

Each subject performed serial $T \mathrm{~L}, \mathrm{CO}$ measurements on each of two randomized treatment days (Control vs $\mathrm{N}_{2} \mathrm{O}$ ) at $30 \mathrm{~min}$ intervals for $3 \mathrm{~h}$. TL,CO measurements were 
performed in triplicate at each time-point. The first timepoint on each day served as a baseline measurement. Following the baseline measurement on the $\mathrm{N}_{2} \mathrm{O}$ day, each subject inhaled Entonox for $10 \mathrm{~min}$ at tidal breathing rates $\left(8-10 \mathrm{~L} \cdot \mathrm{min}^{-1}\right) . T \mathrm{~L}, \mathrm{CO}$ measurements were performed using the Sensormedics 2200 TL,CO cart (Sensormedics Corporation, Yorba Linda, CA, USA), which uses infra-red analysers for determination of $\mathrm{CO}$ concentration. Thus, each subject served as their own control.

In order to confirm the effects observed as being entirely due to a measurement error associated with infrared technology, the identical protocol was repeated on three of the original five subjects using the Med Graphics TL,CO cart (Medica Graphics Corporation, St. Paul, MN, USA) which uses gas chromatography for determining the $\mathrm{CO}$ concentration.

Informed consent was obtained from all subjects, together with approval from the local Ethics Committee for the experimental protocols.

\section{Analysis}

Data for each method of $T \mathrm{~L}, \mathrm{CO}$ determination was analysed using paired t-tests. Total carboxyhaemoglobin $(\mathrm{COHb})$ was determined in two of the three subjects before and immediately following the final $T \mathrm{~L}, \mathrm{CO}$ measurement on the control day, when the gas chromatography method for $T \mathrm{~L}, \mathrm{CO}$ determination was being used. These results were used to assess the cumulative effect of $\mathrm{CO}$ inhalation over the entire $3 \mathrm{~h}$ test period.

\section{Results}

Figure 1 shows the mean TL,CO using the infra-red method ( $n=5$ subjects) and gas chromatography method

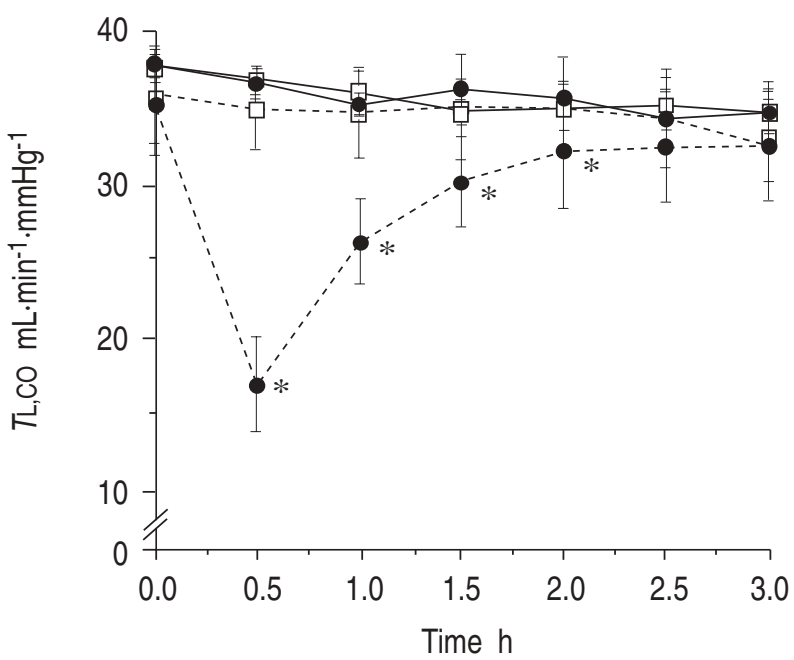

Fig. 1. - Time course of changes in transfer factor of the lung for carbon monoxide ( $T \mathrm{~L}, \mathrm{CO})$ using the infra-red method (IR) (broken lines) versus the gas chromatography method (GC) (solid lines). Values are presented as mean \pm SE. - - - - - - : IR control; - - - - - - : IR $\mathrm{N}_{2} \mathrm{O}$; $\square-$ GC control; $\longrightarrow \longrightarrow$ - $\mathrm{GC} \mathrm{N}_{2} \mathrm{O} .{ }^{*}: \mathrm{p}<0.05$, compared to gas chromatography method
( $\mathrm{n}=3$ subjects) for paired t-tests at each time-point (Control $v s \mathrm{~N}_{2} \mathrm{O}$ ). There was a significant reduction in $T \mathrm{~L}, \mathrm{CO}$ measured with the infra-red method following a $10 \mathrm{~min}$ inhalation of $\mathrm{N}_{2} \mathrm{O}$, and this reduction persisted for at least $2 \mathrm{~h}$. In contrast, there was no significant reduction in $T \mathrm{~L}, \mathrm{CO}$ following the $\mathrm{N}_{2} \mathrm{O}$ inhalation when using the gas chromatography method.

The mean $\mathrm{COHb}$ ( $\mathrm{n}=2$ subjects) prior to performing any $T_{\mathrm{L}, \mathrm{CO}}$ tests on the gas chromatography control day was $1.1 \%$. This increased to $12.1 \%$ following the final time-point when 21 single-breath $T_{\mathrm{L}}$, CO tests had been performed. The difference between the $T \mathrm{~L}, \mathrm{CO}$ corrected for $\mathrm{COHb}$ vs the uncorrected $T \mathrm{~L}, \mathrm{CO}$ at the first timepoint was less than $0.5 \mathrm{~mL} \cdot \mathrm{min}^{-1} \cdot \mathrm{mmHg}^{-1}$. In comparison, the mean difference at the last time point was 4.0 $\mathrm{mL} \cdot \mathrm{min}^{-1} \cdot \mathrm{mmHg}^{-1}$. This demonstrates the likelihood that the reduction in $T \mathrm{~L}, \mathrm{CO}$ after the $3 \mathrm{~h}$ of measurements on both treatment days and in both methods of measurement was probably due to a raised level of $\mathrm{COHb}$.

\section{Discussion}

The results clearly demonstrate that the presence of $\mathrm{N}_{2} \mathrm{O}$ in expired gas can markedly reduce the transfer factor of the lungs for carbon monoxide, when determined using infra-red analysers. This reduction is entirely due to a measurement error and has no physiological basis. In a recent letter, GILBERT [2] reported a similar observation, although without experimental verification. These findings have important ramifications for the interpretation of lung function testing, and necessitate the careful recording of an appropriate history prior to the conduction of $T \mathrm{~L}, \mathrm{CO}$ tests when using infra-red analysers. Textbook descriptions [3] of rapid elimination of $\mathrm{N}_{2} \mathrm{O}$ from the lungs may provide a false sense of security, even when there is awareness of previous administration of Entonox. If the separation of $\mathrm{N}_{2} \mathrm{O}$ and $\mathrm{CO}$ is technically difficult to achieve when using infra-red analysers, then a period of at least $3 \mathrm{~h}$ should be allowed following $\mathrm{N}_{2} \mathrm{O}$ inhalation before a measurement of transfer factor of the lungs for carbon monoxide is performed.

Acknowledgements: The authors would like to thank P. Robertson and M. Parmentier from the Respiratory Investigation Unit, Royal North Shore Hospital for their assistance and S. Anderson for allowing them to use the Med Graphics cart at the Royal Prince Alfred Hospital in Sydney.

\section{References}

1. Hewlett Packard 4721 OA Capnometer. Operating Guide. Section H. Principles of measurement. Part A. Infrared Measurement Technique. January, 1982.

2. Gilbert R. False-low carbon monoxide diffusing capacity measurement after general anaesthesia (Communications to the Editor). Chest 1996; 109: 592.

3. Goodman Gillman A. The Pharmacological Basis of Therapeutics. 8th edn. In: Goodman Gilman A, Rall TW, Nies AS, Taylor P eds. Oxford, Pergamon Press, 1990. 